\title{
Eficacia del programa de reintegración en el departamento del Cauca 2003-2015*
}

\section{Efficacy of reintegration program in the Department of Cauca, 2003-2015}

\author{
William Darío Chará Ordóneze, ${ }^{* *}$ Julián Andrés Valdés Mosquera ${ }^{* * *}$
}

\begin{abstract}
** Politólogo (Universidad del Cauca), Mg. en Sociología (Facultad Latinoamericana de Ciencias Sociales Flacso-sede Ecuador). Docente del programa de Derecho de la Corporación Universitaria Autónoma del Cauca. Coordinador del semillero de investigación en conflicto armado, derechos humanos y justicia transicional. Correo: william.chara.o@uniautonoma.edu.co.

*** Estudiante de último semestre del programa de Derecho de la Corporación Universitaria Autónoma del Cauca e integrante del semillero de investigación en conflicto armado, derechos humanos y justicia transicional. Correo: julian.valdes.m@uniautonoma.edu.co
\end{abstract}

Cómo citar: Chará, W.D; Valdés, J. A (2016). Efectividad de la aplicación de la justicia transicional en el delito de secuestro en Colombia. Inciso. 18 (1); 59-69.

doi: http://dx.doi.org/10.18634/incj.18v.1i.521

Recibido: 18/02/2016 Revisado: 15/03/2016 Aceptado: 13/06/2016

\section{Resumen}

El siguiente artículo busca evidenciar los logros del programa de atención a la población desmovilizada de grupos armados ilegales adelantado por la Agencia Colombiana para la Reintegración en el departamento del Cauca entre los años 2003 al 2015. Con el ánimo de establecer la eficacia de la intervención institucional y la coherencia con la legislación nacional en materia de reintegración, el diseño metodológico se basa en el análisis documental de la legislación colombiana que reglamenta la atención a la población reintegrada y el análisis de datos agregados de la información estadística de la Agencia Colombiana para la Reintegración con lo cual se logra evidenciar avances del programa de atención en ejes como la formación educativa, la reintegración a la vida civil y el fomento de emprendimientos productivos, todo ello, en un contexto de creciente vinculación de población desmovilizada al programa en el Cauca, un departamento con presencia de múltiples actores armados ilegales.

Palabras clave: Agencia Colombiana para la Reintegración, Reintegración, grupos armados ilegales, conflicto armado, legislación, departamento del Cauca.

\begin{abstract}
The following article evidences achievements of the program of attention to population demobilized from illegal armed groups performed by the Colombian Agency for Reintegration in the Department of Cauca between 2003 and 2015.

In order to establish the efficacy of institutional intervention and coherence with national law in matters of reintegration, the methodological design is based on documental analysis of the Colombian laws governing attention to reintegrated population, and analysis of aggregated statistical data provided by the Colombian Agency for Reintegration, in order to evidence the progress of such attention program in axles such as educative formation, reintegration to the civilian life, and promotion of productive undertakings, everything within a context of growing inclusion of demobilized population into the program in the Department of Cauca, a department undergoing presence of many illegal armed actors.
\end{abstract}

Keywords: Colombian Agency for Reintegration, reintegration, illegal armed groups, armed conflict, law, Department of Cauca.

\footnotetext{
* Este artículo hace parte de la investigación titulada "Conflicto armado, Derechos Humanos y Justicia Transicional en el departamento del Cauca (20102015)" adscrita al programa de Derecho de la Corporación Universitaria Autónoma del Cauca (Popayán).
} 


\section{Introducción}

En la historia del conflicto armado interno han existido diferentes programas institucionales de reintegración a la sociedad civil de excombatientes de grupos armados ilegales a partir de negociaciones y acuerdos de garantías de desmovilización ofrecidos por el Estado colombiano. "Las primeras negociaciones de paz adelantadas con grupos guerrilleros del M19, el EPL, el PRT, el Movimiento Quintín Lame y la Corriente de Renovación Socialista desarmaron 5700 personas" (Mejía, 2014:16). Por su parte las Autodefensas Unidas de Colombia entregaron 35 353 combatientes y de grupos guerrilleros como las Farc, el ELN, el EPL, el ERG y el ERP, a 2016, se han desmovilizado 18882 personas. (Agencia Colombiana para la Reintegración, 2015)

Para garantizar una atención a la población de excombatientes y garantizar las medidas que limiten la vinculación a nuevos grupos armados ilegales así como a otras formas de criminalidad, el Estado colombiano fijó mecanismos de atención que nacen en la década de 1980, los cuales han presentado algunas variaciones y alcances dependiendo no solo de la disposición institucional sino de los mismos ritmos de la confrontación armada y los intentos de procesos de paz.

Los programas de reintegración para personas desmovilizadas de grupos al margen de la ley se remonta al año 2003 cuando se crea el Programa para la Reincorporación a la Vida Civil de Personas y Grupos Alzados en Armas (de ahora en adelante PRVC) esta entidad estuvo adscrita al Ministerio de Interior y de Justicia hasta el año 2006. El PRVC tenía la función de brindar atención psicosocial, beneficios y servicios a personas desmovilizadas.

Una evaluación muy general del PRVC como estrategia de reintegración de excombatientes de actores armados ilegales se resumen del siguiente modo:

El programa no tuvo gran protagonismo durante el primer año de funcionamiento. Sin embargo, en una coyuntura de continuas desmovilizaciones colectivas, el PRVC estuvo sujeto a múltiples críticas por parte de la opinión pública, que se centraron en los siguientes aspectos: la estructura del PRVC; los procedimientos para acceder a los beneficios del programa y la ausencia de coordinación institucional, tanto horizontal como vertical; y el trato diferencial brindado a los desmovilizados individuales y colectivos en la entrega de la ayuda humanitaria. (Giraldo, 2010:39)

La poca capacidad estatal se ha relacionado con la débil respuesta de cobertura y estructura institucional para atender la demanda de la población excombatiente. Según Villarraga (2013) existe un ejercicio de planificación entre las instituciones encargadas y un fuerte apego la evolución normativa de atención y garantía de derechos de población en proceso de reintegración que llevó a que las desmovilizaciones masivas, especialmente desde grupos paramilitares, estuvieran motivadas más por los beneficios jurídicos que la ley ofrecía que por la oportunidad de reintegración social y económica de los programas. Así:

De las más de 35 mil personas aceptadas en calidad de paramilitares desmovilizados, solo entre 3 y 4 mil se postularon para la Ley 975 de 2005, quienes tenían o podían tener investigaciones por graves violaciones. Pero los restantes, más de 30 mil, inicialmente obtuvieron de manera directa el indulto, en aplicación del Decreto 128 de 2003. (Villarraga, 2013:128)

Estas razones se deben a que como expone Nussio (2012:58-59) también pone de presente las mayores dificultades en la primera década del siglo XXI con relación a contextos de violencia e ilegalidad críticos, y limitaciones estatales que afectan las posibilidades de la reintegración de los ex paramilitares, teniendo en cuenta factores como falta de educación, oferta laboral y a estos se le suma los altos niveles de penumbra en los que viven, por lo cual pasan a ser víctimas de la violencia.

Sin embargo Koth (2005), corroborando lo expuesto por Nussio (2012), asevera que los programas de atención y de reintegración son incompletos lo que puede colocar a los excombatientes en objetivos de otros grupos o en defecto a que estos decidan abandonar los programas ofertados por el gobierno. Con la promulgación de la Ley 975 de 2005 se creó la Alta Consejería Presidencial para la Reintegración, 
la cual tendría como objetivo principal atender la mayor demanda de población desmovilizada, algo que critica Gonzales (2010) al mencionar que no se han podido unir lazos entre la población víctima y victimario.

Bajo estas ópticas de limitación institucional de los programas, la Fundación Seguridad y Democracia (2007) plantea que los procesos de reintegración por parte del Estado colombiano no han logrado mayor impacto debido al rearme y control de territorios por parte de grupos ilegales nacidos a la sombra de las desmovilizaciones de grupos paramilitares del año 2016. Es decir, que las dinámicas de la continuidad del conflicto armado interno han experimentado no solo la intensificación de las acciones armadas sino también nuevas modalidades de organización criminal que han llevado a la reincidencia en algunos casos, con lo cual se impide el proceso de reintegración efectivo (Giraldo, 2010).

Si bien es cierto el conflicto es un fenómeno social más arraigado en los países latinoamericanos, especialmente en Colombia y es por ello que como principio de justicia transicional aparece garantías de no repetición; dentro de ella se encuentra los procesos de reintegración que consisten en desarrollar habilidades y competencias ciudadanas entre las personas desmovilizadas y sus entornos. Al mismo tiempo, se propone propiciar espacios para la convivencia y acciones de reconciliación, y fomentar la corresponsabilidad de los actores externos. Por lo cual es necesario el apoyo de las instituciones nacionales, regionales y locales entre ellos, la Agencia Colombiana para la Reintegración (Agencia Colombiana para la Reintegración, 2011).

Es en el marco institucional, y evidenciando las desmovilizaciones de grupos armados en momentos de intensificación y reducción de la intensidad del conflicto armado, que este artículo de investigación busca determinar no solo el balance del programa de reintegración de ex combatientes en el departamento del Cauca en el periodo 2003-2015 sino también establecer los alcances y desafíos institucionales que enfrenta el programa y la población beneficiaria frente al contexto de posconflicto que se avecina.

\section{Metodología}

Para la realización de este artículo de investigación, metodológicamente se requirió la combinación de dos técnicas de investigación, una de nivel cualitativo: análisis documental, y otra de nivel cuantitativo: análisis de datos agregados.

A partir del análisis documental, desde un enfoque de hermenéutica jurídica, se procedió a seleccionar y analizar la información contenida en la normatividad referida a garantizar la reintegración de población excombatiente de grupos armados ilegales, entre las que se encuentran la Ley 975 de 2005, el Decreto 3043 de 2006 y el Decreto 4138 de 2011, así como también las estrategias definidas por los programas de atención institucional para la reintegración. A partir de esta información se logró identificar el marco normativo tendiente al análisis de la eficacia de la intervención institucional a la reintegración.

Una vez identificada la normatividad, la eficacia de la acción institucional comprendió el análisis de datos agregados a partir de la información estadística brindada por la Agencia Colombiana de Reintegración en su página Web. La selección, procesamiento de bases de datos y análisis de información permitieron caracterizar los avances del programa a nivel departamental, logrando con ello evidenciar el avance en el cumplimiento de los lineamientos normativos y procedimentales del programa a nivel departamental.

\section{Resultados}

El DDR tiene como marco jurídico la Ley 418 de 1997, prorrogada por la Ley 548 de 1999, la Ley 782 de 2002, la Ley 1106 de 1997 y la Ley 1421 de 2010 las cuales establecen que las personas desmovilizadas, colectiva o individualmente, tiene derecho a os beneficios de los procesos de reintegración social y económica.

Los programas de reintegración para personas desmovilizadas de grupos armados ilegales se remontan al año 2003 cuando se crea el Programa para la Reincorporación a la Vida Civil de Personas y Grupos Alzados en Armas (PRVC). Este programa tuvo pocos resultados en términos de reintegración de desmovilizados a la vida civil, toda vez que, ante 
la desmovilización masiva de integrantes de grupos paramilitares luego de la aprobación de la Ley 975 de 2005 (Ley de Justicia y Paz) y la ya inclusión de excombatientes de grupos guerrilleros, el PRVC se congestionó administrativa, fiscal y operativamente obteniendo como resultado poca eficacia. Esta situación obligó al Estado a reestructurar la política de reintegración y obligando a la creación de una institución que pudiera atender la demanda de desmovilizados.

Ante tal panorama, en año 2006 se expide el Decreto 3043 que crea la Alta Consejería para la Reintegración Social y Económica de Personas y Grupos Alzados en Armas. Esta tuvo carácter de Departamento Administrativo adscrito a la Presidencia de la República y tuvo como funciones el Plan de Desmovilización, Desarme y Reintegración (DDR) que cobijaba a los desmovilizados individuales como también a los colectivos, brindándoles mayor capacidad de cobertura en atención, gestión de recursos y mejor acompañamiento a partir de rutas de reintegración con beneficios de tipo psicosocial, educativo, económico y de generación de ingresos para contribuir a la reinserción a la vida civil.

Para el año 2011, el gobierno de Juan Manuel Santos Calderón decide crear la Agencia Colombiana para la Reintegración (ACR) bajo el Decreto 4138 de 2011 como una unidad administrativa especial con personería jurídica adscrita al Departamento Administrativo de la Presidencia de la República, con las mismas funciones que la Alta Consejería para la Reintegración Social y Económica de Personas y Grupos Alzados en Armas, pero cabe anotar, con una mayor autonomía financiera, administrativa y presupuestal en un contexto de intensificación de las acciones institucionales para contrarrestar el conflicto armado interno.

\section{El avance del programa de resocialización en Colombia}

En la actualidad, la Agencia Colombiana para la Reintegración (en adelante ACR) es la encargada por mandato legal de orientar los programas de reintegración y estima que en el periodo 2003 al 2015 cerca 57.609 personas se desmovilizaron de grupos armados ilegales (ARC, 2015). De esta población desmovilizada no toda ingresó al programa de reintegración. Del total de personas desmovilizadas a nivel nacional, 8997 no decidieron ingresar al programa o no cumplieron con los requisitos de Ley establecidos por la ACR. Es decir, que desde el inicio de la estrategia hasta el 2015, el programa ha intervenido a 48612 excombatientes.

Según la Figura 1, en el departamento del Cauca, a diferencia de la dinámica nacional, las desmovilizaciones masivas no tienen como punto más alto el año 2006 sino el año 2008. Si bien en 2006 existen desmovilizaciones de cerca del 17.3 $\%$, estas se relacionan con grupos paramilitares que hicieron presencia en el norte del Cauca y en menor medida en el sur del departamento, mientras que las de 2008 y los años siguientes hacen referencia a las desmovilizaciones de grupos guerrilleros, especialmente de las FARC y el ELN cuyas desmovilizaciones han sido mayoritariamente $(60 \%)$ individuales y por ello más esporádicas en el tiempo.

Figura 1. Población desmovilizada de grupos armados en proceso de reintegración. 2003-2015

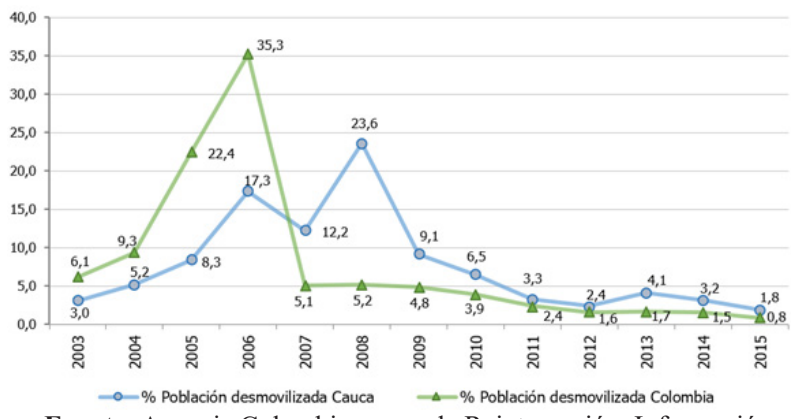

Fuente: Agencia Colombiana para la Reintegración. Información a diciembre de 2015

Para la atención de esta población desmovilizada, el diseño de programas y dimensiones se implementaron a partir del Conpes 3554 de 2008 que estableció la Política Nacional de Reintegración, la cual se enmarca como un plan de Estado y de sociedad que busca promover la incorporación efectiva del desmovilizado con voluntad de paz y de su familia a las redes sociales del Estado y a las comunidades receptoras. (Conpes, 2008). 
Así, el programa de reintegración propuesto por la ACR, cuenta con 8 dimensiones que forman el marco de la ruta de la reintegración con el único fin de garantizar el pleno desarrollo de potencialidades y de ejercicio de ciudadanía de la población desmovilizada en procura de mejorar sus condiciones sociales y de calidad de vida para la reintegración efectiva en la sociedad civil.

Estas dimensiones son: 1) Dimensión personal: la cual contribuye a la salud mental y la relación individuo-sociedad. 2) Dimensión salud: que busca garantizar estilos de vida saludables a partir de la promoción de la salud física, mental y social. 3) Dimensión familiar: que brinda acompañamiento en el proceso de reintegración familiar, convivencia y promoción de entornos protectores de la familia. 4) Dimensión educativa: apoyar en la formación educativa para la realización de proyectos de vida. 5) Dimensión productiva: apoyo en la generación de emprendimientos productivos. 6) Dimensión de Habitabilidad: busca el apoyo al mejoramiento de condiciones óptimas para la mejorar la calidad de vida y bienestar. 7) Dimensión Ciudadana: apoyo al fortalecimiento de calidades sociales para la convivencia. 8) Dimensión de Seguridad: Promueve la gestión del riesgo, la victimización y la reincidencia (Agencia Colombiana para la Reintegración, 2011: 5-11).

A nivel nacional, estas estrategias han contemplado la atención a 48.612 excombatientes de grupos armados ilegales desde el 2003 al 2015. (Agencia Colombiana para la Reintegración, 2016)

\section{El Programa de Reintegración en el departamento del Cauca}

Muy por el contrario a la larga historia del conflicto armado en el departamento del Cauca, que se ha expresado en las 264180 víctimas aproximadamente hasta febrero de 2016 (Unidad para la Atención y Reparación Integral de Víctimas, 2016), la presencia de todos los actores armados, dinámicas de narcotráfico y nuevos actores controlando territorios, las desmovilizaciones han tenido un comportamiento diferencial a lo que podría esperarse. En un departamento en donde aún se sigue expresando el conflicto armado en todas sus dimensiones e intensidades, la población desmovilizada de grupos armados ilegales que han accedido a los beneficios del programa de reintegración corresponde tan solo al $1,7 \%$ del total nacional.

Según la Tabla 1, (ver sig pág ) desde el 2003 al 2015 según datos de la Agencia Colombiana de Reintegración, en el departamento del Cauca las desmovilizaciones tanto colectivas o individuales han sumado 757 personas en total. Sin embrago, la población desmovilizada que fue censada y que no accede al programa corresponde al $11.9 \%$ de esta población. Así, en el departamento del Cauca en el periodo de estudio al programa han accedido 729 excombatientes.

De los 729 integrantes censados del programa, solo 531 han sido atendidos por el programa pues 116 se consideran población ausente de proceso, lo que estaría windicando que, por un lado sin seguimiento a esta población es alta la posibilidad de reinserción sus antiguos grupos armados o nuevos grupos ligados al narcotráfico y a lazos de extintos paramilitares, y por el otro lado un descontento de la población que ingresó.

Respecto al número de personas desmovilizadas que hacen parte del programa, según datos de la ACR, en el departamento del Cauca el $12 \%$ son considerados como población de alto riesgo. Por su parte, en términos de posibilidad de reincidencia en el Cauca, la información de la ACR estima que cerca del 2,6 \% (19 personas) están consideradas como población vulnerable a la reincidencia por parte de nuevos grupos armados ilegales. Por sexo, se evidencia que las personas desmovilizadas que ingresaron al programa son en su gran mayoría hombres $(80.8 \%)$ mientras que las mujeres corresponden al 19.2\%.

Por edad de ingreso al programa, en la figura 2 (ver sig pág) se observa que la población desmovilizada de grupos armados ilegales tiende a concentrarse en edades productivas (entre los 26 y 40 años) muy por el contrario a la idea de la desmovilización de edades mucho más adultas (más de 60 años). A la población en edad productiva le sigue la población entre los 18 y 25 años de edad, la cual evidencia que dentro de las filas, la población desmovilizada indica la posibilidad que estos hayan ingresado a los grupos armados ilegales siendo adolescentes. 
Tabla 1. Población desmovilizada de grupos armados en proceso de reintegración. 2003-2015

\begin{tabular}{cccccccccc}
\hline Departamento & \multicolumn{2}{c}{ Culminados } & \multicolumn{2}{c}{$\begin{array}{c}\text { Población en } \\
\text { proceso }\end{array}$} & \multicolumn{2}{c}{$\begin{array}{c}\text { Población ausente } \\
\text { del proceso }\end{array}$} & $\begin{array}{c}\text { Población fuera } \\
\text { del proceso }\end{array}$ & Total \\
\hline & Total & $\%$ & Total & $\%$ & Total & $\%$ & Total & $\%$ & \\
Nacional & 10626 & 21,9 & 19668 & 40,5 & 9140 & 18,8 & 9178 & 18,9 & 48612 \\
Cauca & 190 & 26,1 & 341 & 46,8 & 116 & 15,9 & 82 & 11,2 & 729 \\
\hline
\end{tabular}

Fuente: Agencia Colombiana para la reintegración. Información a diciembre de 2015.

Figura 2. Población atendida por ARC en el Cauca por grupos armados y edad 2003-2015
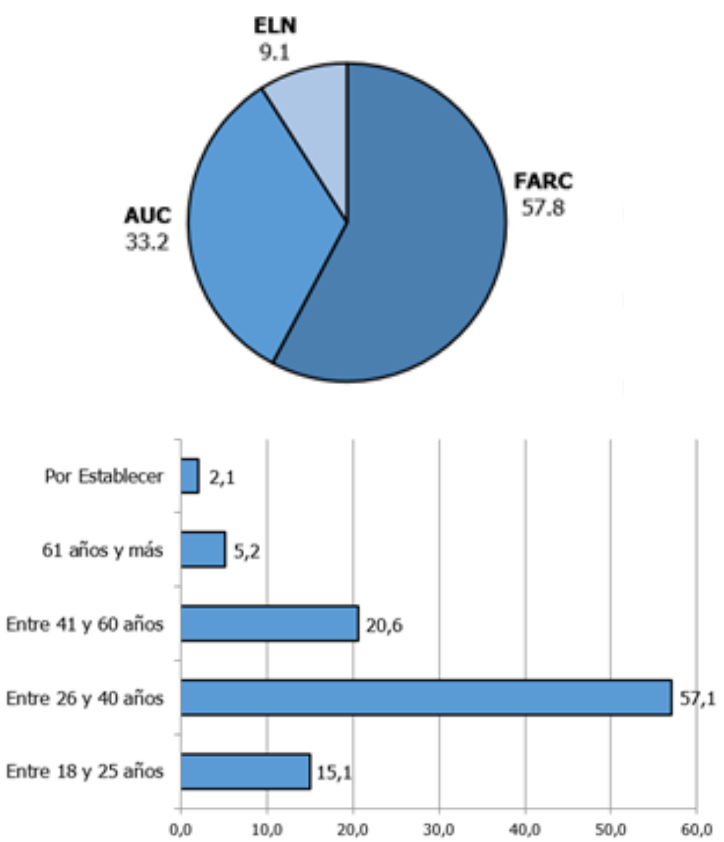

Fuente: Agencia Colombiana para la reintegración. Información a diciembre de 2015.

En términos de eficiencia del programa, es decir, aquella población de excombatientes que finalizaron el programa, resalta la población de primera generación (excombatientes de grupos paramilitares) que culminaron el proceso.
Figura 3. Población atendida por ARC en el Cauca por grupos armados y sexo 2003-2015
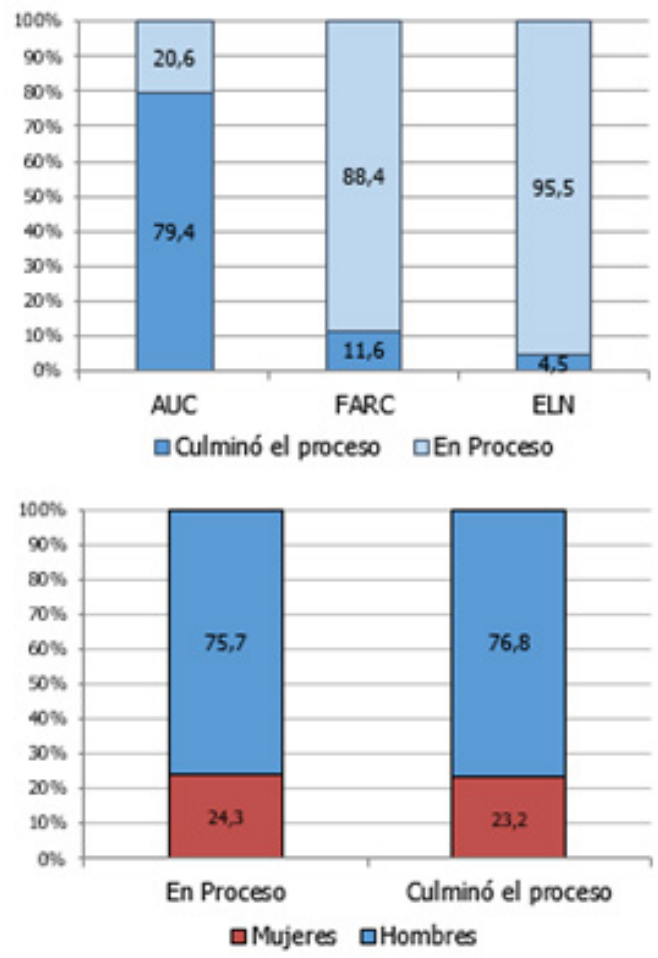

La atención de la población beneficiada por el programa de la ACR en el departamento del Cauca indica que de los ejes de acompañamiento psicosocial, gestión en educación y formación para el trabajo, el primero es el de mayor demanda por la población atendida (70,2\%). Esto indica por un lado la ruta de inicio de atención para la reintegración, así como también la necesidad de la población atendida por iniciar procesos de rehabilitación emocional y psicológicos para enfrentar los retos de una vida por fuera tanto de las armas como de las lógicas victimizantes propias del conflicto armado interno. 
Tabla 2. Población atendida por ARC en el Cauca por tipo de intervención 2003-2015

\begin{tabular}{cccccccc}
\hline Departamento & $\begin{array}{l}\text { Total } \\
\text { atendidos }\end{array}$ & \multicolumn{2}{c}{$\begin{array}{c}\text { Acompañamie } \\
\text { nto psicosocial }\end{array}$} & $\begin{array}{c}\text { Gestión en } \\
\text { educación }\end{array}$ & $\begin{array}{c}\text { Formación para } \\
\text { el trabajo }\end{array}$ \\
\hline Nacional & 23.144 & 23.112 & 1 & 5.817 & 0 & 4.574 & 0 \\
Cauca & 624 & 438 & 70,2 & 96 & 15,4 & 90 & 14,4 \\
\hline
\end{tabular}

Fuente: Agencia Colombiana para la reintegración. Información a diciembre de 2015.

Según los datos de la Tabla 2, resalta que en educación el porcentaje de atendidos sea solo del 15,4 \% y de formación para el trabajo el 14,4\%. Esto indica que es limitada la atención integral para la reincorporación a la vida civil. Sin embargo, algunos elementos que permiten evidenciar la eficacia del programa en otras dimensiones de atención en el departamento del Cauca se presentan a continuación.

Sobre la atención en vivienda, se observa que de la población que ingresó al ACR, la mayoría $(37,5$ \%) vivía en vivienda alquilada. Un valor agregado de éxito del programa se relaciona con el acceso a vivienda propia. De esta población, al culminar el proceso se incrementó al $58.8 \%$, lo cual indica que parte de los beneficios son entregados a la población atendida en el departamento del Cauca.

Muy similar al comportamiento de la población que culminó el proceso, los integrantes actuales viven en vivienda arriendada (49.1\%) o en casas de familiares $(27.5 \%)$ mayoritariamente. El reto con esta población es lograr mantener los mismos resultados que la población que culminó el proceso, es decir, que al finalizar el programa cuenten con vivienda propia. En el Cauca, la tendencia es que la población adquiera su vivienda no solo a partir de subsidios o ayudas económicas por parte del Estado, sino también por medio de la capacidad y fortalecimiento de emprendimientos productivos que permita mejorar sus ingresos y con ello se garantice un proceso de reintegración a la sociedad civil con calidad de vida.

En términos afiliación en salud, Figura 4, el programa ha evidenciado logros significativos en el departamento del Cauca. De la población que culminó el proceso con la ACR, el 76,8 \% está afiliado al régimen subsidiado, mientras que el $20 \%$ al contributivo. Tan solo el 3,2 \% de la población que culminó el proceso está por fuera del sistema de salud nacional. Esto indica que en términos de cobertura en salud el programa de la ACR en el Cauca ha generado logros significativos.

Figura 4. Población atendida por ARC en afiliación a salud en el Cauca 2003-2015

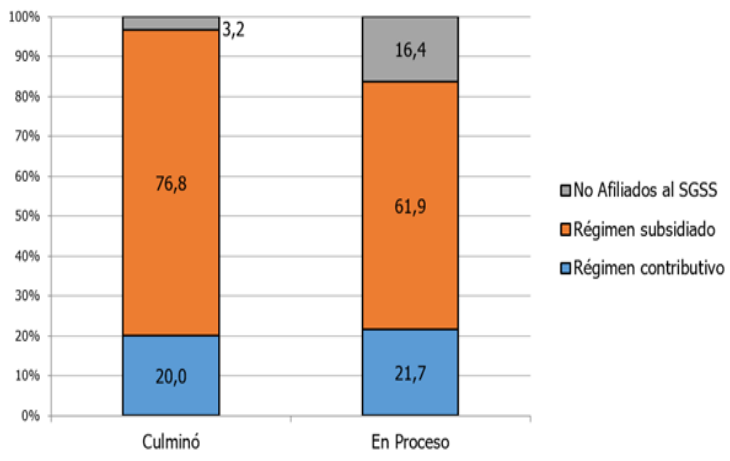

Fuente: Agencia Colombiana para la Reintegración. Información a diciembre de 2015 .

El reto para la ACR es incrementar el $16,4 \%$ de la población en proceso de atención que se encuentra por fuera del sistema de salud nacional.

Tabla 3. Población atendida por ARC en asistencia a educación superior en Cauca 2003-2015

\begin{tabular}{ccccccc}
\hline Programa & \multicolumn{2}{c}{$\begin{array}{c}\text { Técnicos } \\
\text { profesionales }\end{array}$} & \multicolumn{2}{c}{ Tecnólogos } & Universitarios \\
\hline Total & $\%$ & Total & $\%$ & Total & $\%$ \\
Nacional & 67 & 0 & 2.176 & 0 & 466 & 0 \\
Cauca & 5 & 0,69 & 27 & 3,7 & 5 & 0,69 \\
\hline
\end{tabular}

Fuente: Agencia Colombiana para la Reintegración. Información a diciembre de 2015. 
En términos de asistencia en educación, la asistencia de la ACR es limitada. Se observa en la Tabla 3 que son pocos los avances en términos de formación educativa superior. Tan solo el 3,7 \% de la población atendida ha logrado acceder a educación tecnológica, el $0,69 \%$ a educación universitaria.

Si bien esto permitiría colegir que la atención de la ACR en educación es deficiente en el departamento del Cauca y con ello las posibilidades de emprendimientos productivos se reducirían, la ACR ha vinculado también a la población en acciones de servicio social certificadas con lo cual se subsana, no la deficiencia en formación profesional, pero si las capacidades de certificación de oficios y labores para el fomento productivo. Así, se evidencia que la población que terminó el proceso se ha certificado como multiplicadores de conocimientos, en recuperación ambiental y en aporte de habilidades especiales.

Figura 5. Población atendida por ARC en acciones de servicio social en el Cauca 2003-2015

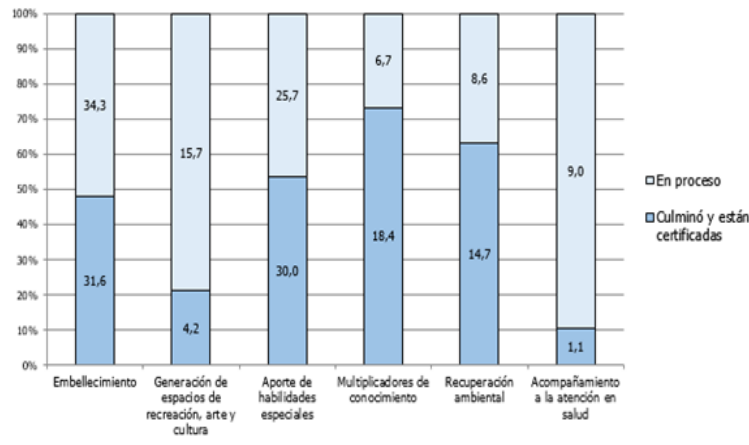

Fuente: Agencia Colombiana para la Reintegración. Información a diciembre de 2015.

Si bien la formación en educación superior no ha logrado las expectativas del programa, la formación en acciones sociales ha contribuido positivamente para la reintegración de la población en el departamento. Un ejemplo fue:

En octubre de 2010, en Popayán se graduaron 250 personas como líderes en convivencia, entre quienes había jóvenes, líderes comunitarios, personas desmovilizadas y víctimas. De acuerdo con lo reportado por la ACR, este es un proceso de formación en competencias ciudadanas que hace parte del proyecto Sueños de Paz operado por la Corporación Manantial y apoyado por la ACR, el Fondo de Programas Especiales para la Paz (Fondopaz) y la Oficina del Alto Comisionado para la Paz. (Centro Nacional de Memoria Histórica, 2014:352)

La formación se relaciona directamente con la creación de emprendimientos productivos de la población que atiende la ACR en el departamento del Cauca. Según los datos, el 24,1\% de los emprendimientos productivos están en funcionamiento a enero de 2016.

Los emprendimientos productivos que están por establecerse son cerca del $61,5 \%$, lo que indica que aún existen limitaciones para el fomento productivo en especial por entrega de certificados de funcionamiento y en algunos casos la falta de capital inicial para el emprendimiento. El reto institucional será consolidar este $61,5 \%$ en emprendimientos productivos exitosos y sostenibles. Ante este panorama, se puede colegir un cierto nivel de éxito del programa de la ACR pues tan solo el $0,5 \%$ de los emprendimientos han sido cerrados o declarados inexistentes.

\section{Discusión de los resultados: Los retos del programadereintegración en el departamento del Cauca}

El programa de reintegración de la ACR enfrenta varios retos que van desde el nivel institucional hasta los desafíos mismos de las dinámicas del conflicto armado interno.

A nivel nacional, el inicio de la estrategia de la ACR enfrentó dificultades en términos de atención y cobertura. Así, la afiliación en salud y los programas de fomento productivo no había podido beneficiar más del $40 \%$ de la población desmovilizada, con lo cual se generó en los desmovilizados el retorno al ejercicio de actividades ilícitas y la aparición de nuevas estructuras de corte paramilitar ligadas al narcotráfico (Fundación Seguridad y Democracia, 2007:14).

Respecto a lo anterior, una de las deficiencias de la Ley de Justicia y Paz no fue la creación de un nuevo pacto, sino que solo trató temas centrales como 
la desmovilización de un grupo de combatientes pertenecientes a paramilitares y no la reintegración de estos. Al respecto:

Se enfocó en lograr que la Reintegración se convirtiera en una política de Estado. Así, buscó brindar oportunidades a las personas desmovilizadas mediante una Ruta de Reintegración personalizada con beneficios de tipo psicosocial, educativo, económico y de oportunidades de generación de ingresos, con el fin de permitir que los desmovilizados encuentren una vida sostenible en la civilidad. La Alta Consejería no sólo buscó implementar estrategias enfocadas hacia los participantes en Proceso de Reintegración, sino también en las familias y comunidades que los reciben, bajo la concepción de que la sostenibilidad de la Reintegración a la vida en la legalidad implica trabajar no sólo con el desmovilizado, sino también con su entorno. (Agencia Colombiana para la Reintegración, 2015:7).

Si bien es cierto que los programas de reintegración sirven para reincorporar a un excombatiente a la vida civil, este proceso no puede ser culminado satisfactoriamente por muchos factores, entre ellos los homicidios cometidos por otros grupos insurgentes, lo cual los posiciona en una situación de vulnerabilidad. De otro lado las capturas de personas que hacen parte de los programas ofertados por las instituciones encargadas para estas responsabilidades. (Defensoría del Pueblo, 2005).

En el difuso ambiente institucional y normativo, también es pertinente indicar que el Estado ha cumplido parcialmente con lo prometido por la ACR. $\mathrm{Al}$ respecto, resulta pertinente indicar:

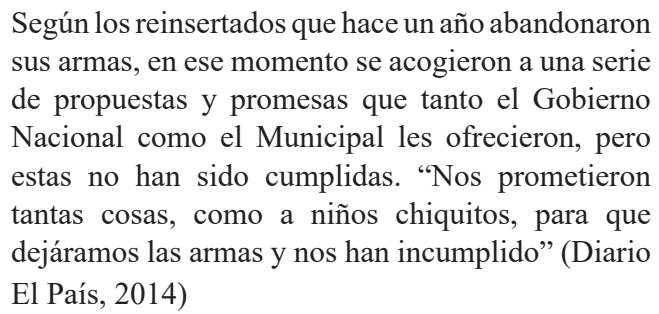

Esto permite establecer que aún existen dificultades institucionales y normativas para el desarrollo óptimo del programa de reintegración de la ACR que requieren ser atendidas y resueltas en el menor de los tiempos, toda vez que la institucionalidad pública deberá no solo garantizar el proceso de reintegración sino también aportar legitimidad para el sostenimiento del programa.

La otra cara de la moneda se refleja en las dificultades por parte de la población atendida por la ACR que conlleva a la no conclusión de los programas de atención y con ello una reintegración limitada. Uno de los elementos que impiden la culminación exitosa del programa se relaciona con las dificultades de adaptabilidad de la población beneficiada. Algunos casos, documentados por el Observatorio de Desarmes, Desmovilización y Reintegración (2008):

Desde el 2008, el joven reside con su familia. Como beneficios de la ruta de reintegración de la ACR ha recibido acompañamiento psicosocial y la oportunidad de terminar la primaria. Se siente inconforme con su proceso en el municipio donde reside con su familia y contempla la posibilidad de restablecerse en la ciudad de Cali junto a otros familiares (Observatorio de Desarmes, Desmovilización y Reintegración, 2008:46)

El segundo elemento que limita el proceso de reintegración se relaciona con la reincidencia en actividades delictivas que según el Diario el País (2014) a diciembre de 2014 cerca de $26 \%$ de desmovilizados fueron excluidos del programa de atención de la ACR. Al respecto, la Comisión Nacional de Reparación y Conciliación (2010) señala que:

La observación realizada constató notables situaciones de reincidencia de sectores de desmovilizados en el delito y su participación en hechos de violencia y en grupos armados ilegales, para lo cual se cruzó información relativa a situaciones como las capturas, las muertes en enfrentamientos con la Fuerza Pública, otras circunstancias y algunos informes y testimonios conocidos en las regiones (Comisión Nacional de Reparación y Conciliación, 2010:12).

En los contextos de reincidencia, entre el 2001 y 2009 fueron capturados 5.890 desmovilizados por acciones delincuenciales asociadas a crimen organizado y murieron 2.210 en confrontaciones con fuerzas armadas o por dinámicas propias del accionar criminal (Comisión Nacional de Reparación y Conciliación, 2010). 


\section{Conclusiones}

En el departamento del Cauca, la primera de las conclusiones es el descenso de las desmovilizaciones desde el año 2009, en comparación con el incremento de la población que ingresó al programa de reintegración de la ACR en el 2007. Ello, en un departamento aún con presencia de grupos guerrilleros (FARC y ELN) en zonas del sur, occidente y oriente del departamento.

De la población que ingresó al programa (que concluyó y aquella que aún está en proceso), los avances en términos de afiliación en salud, seguridad, vivienda y atención psicosocial ha generado resultados positivos si se observa no solo los datos de ejecución de la ACR en el periodo 2003 - 2015, sino también la creación de emprendimientos productivos y fortalecimiento de capacidades para la reintegración y adaptación social a la vida civil.

La segunda de las conclusiones indica que la relación de reincidencia en el departamento del Cauca es menor a la nacional (ACR, 2015), sin embargo este dato reviste importancia por la presencia aún de grupos guerrilleros y de bandas criminales, principalmente en el sur y occidente del departamento (Chará, 2016), las cuales han demostrado una cercana relación con el narcotráfico y el control de territorios para sus acciones delictivas.

En términos de reintegración de población desmovilizada, el trabajo de la ACR en el Cauca ha sido eficaz en fomentar emprendimientos productivos, cobertura en afiliación a salud y el acompañamiento en casos de reparación y verdad en el marco del Proceso de Justicia y Paz. La ACR ha buscado brindar acompañamiento no sólo a la población desmovilizada sino también a las personas víctimas del conflicto armado. Con la visibilidad del trabajo, la ARC y la población reintegrada buscan aportar a los procesos de reparación integral de las víctimas y la garantía de no repetición de las acciones.

Finalmente, si bien existen pruebas documentales de la eficacia del programa en el departamento del Cauca que permiten resaltar el cumplimiento por parte del Estado a las personas desmovilizadas, tanto los datos agregados de la ACR como la información brindada por la población reintegrada por el programa evidencian cumplimiento de las actividades planificadas y una eficacia en los objetivos trazados por la institucionalidad pública.

En ese sentido, el reto del programa de reintegración es mantener la eficacia en el cumplimiento de sus objetivos, máxime en un departamento que ha experimentado el conflicto armado con intensidad y que se propone como departamento piloto en intervención institucional para el posconflicto. Así, los objetivos trazados por la ACR deben seguir orientados a generar mayor confianza institucional y garantizar integralmente la adaptación a la vida civil de todas aquellas personas desmovilizadas que han ingresado al programa, mejorando atención en educación, ampliando la cobertura en salud al 100 $\%$ y garantizando mecanismos de sostenibilidad al $60 \%$ de los emprendimientos productivos que están por formalizarse. Solo así, con atención y cobertura integral se podrá garantizar la calidad de vida de la población reintegrada no solo en el departamento del Cauca, sino también, en todo el territorio nacional.

\section{Referencias bibliográficas}

Agencia Colombiana para la Reintegración. (2011). Informe Anual de Gestión Alta Consejería para la Reintegración Social y Económica de Personas y Grupos Alzados en Armas. En: http://www.reintegracion.gov.co/es/ agencia/Documentos\%20Informes $\% 20$ de $\% 20$ gestin/Informe $\% 20$ de $\% 20$ gesti $\%$ C3 \%B3n\%201\%202010-2011.pdf

Agencia Colombiana para la Reintegración. (2015). Manual del Sistema Integrado de Gestión para la Reintegración. En: http:// www.reintegracion.gov.co/es/agencia/ Documentos $\% 20 \mathrm{de} \% 20$ Siger $/ 2015 \quad \% 20$ 1\%20Manual\%20de1\%20SIGER\%20v2. PDF

Agencia Colombiana para la Reintegración. (2016). La Reintegración en cifras. Información estadística a diciembre de 2015. En: http://www.reintegracion.gov.co/es/ la-reintegracion/Paginas/cifras.aspx 
Centro Nacional de Memoria Histórica. (2014). Nororiente y Magdalena Medio, Llanos Orientales, Suroccidente y Bogotá Dc Nuevos Escenarios de Conflicto Armado y Violencia Panorama pos acuerdos con AUC. Colombia: Centro Nacional de Memoria Histórica.

Chará, W. (2016). Las víctimas del conflicto armado en el departamento del Cauca. Working paper. Corporación Universitaria Autónoma del Cauca.

Comisión Nacional de Reparación y Conciliación. (2010). La reintegración: logros en medio de rearmes y dificultades no resueltas. Colombia: Comisión Nacional de Reparación y Conciliación.

Conpes 3554 de 2008 (01 de diciembre). Política Nacional De Reintegración Social y Económica para Personas y Grupos Armados Ilegales.

Defensoría del Pueblo. (2005). Informe de Seguimiento a la Desmovilización Colectiva y Proceso de Reincorporación de Miembros de las Autodefensas Unidas de Colombia Noviembre de 2003 - Abril de 2005. En: $\quad$ file:///D:/mis\%20documentos\%20 seven/Downloads/desmovilizaci\%C3 $\%$ B3n\%20colectiva.pdf

Decreto 3043 de 2006 (07 de septiembre). Por el cual se crea una Alta Consejería en el Departamento Administrativo de la Presidencia de la República. Diario oficial 46384.

Decreto 4138 de 2011 (03 de noviembre). Por el cual se crea la Agencia Colombiana para la Reintegración de Personas y Grupos Alzados en Armas y se establecen sus objetivos y estructura. Diario oficial 48242.

Fundación Seguridad y Democracia. (2007). La reinserción paramilitar: un balance. Coyuntura de sociedad, 10, 14-20.
Giraldo, S. (2010). Contextualización teórica e histórica de la reintegración social y económica de desmovilizados en Colombia. Poliantea 6 (11), 35-52.

Gonzales. A (2010). Justicia transicional y reparación a las víctimas en Colombia. Revista Mexicana de Sociología (72), 629-658.

Koth, M. (2005). To End a War: demobilization and reintegration of Paramilitaries in Colombia. Germany: Bonn International Center for Conversion

Mejía, L. (2014). La reintegración social y económica de los grupos armados ilegales en Colombia: reflexiones a partir de la trayectoria de nueve excombatientes. Tesis para optar por el título de Maestría en Estudios Políticos y Sociales. Universidad Colegio Mayor de Nuestra Señora del Rosario. Bogotá.

Nussio, E. (2012). Desarme, desmovilización y reintegración de excombatientes: Políticas y actores del posconflicto. Colombia internacional (77), 08-16.

Villarraga, A. (2013). Experiencias históricas recientes de reintegración de excombatientes en Colombia. Colombia internacional (77), 107-140. 